\title{
Storage, processing and visualization data system of drifter observations of surface currents in the World Ocean
}

\author{
O. P. Nikitin ${ }^{1}$ \\ Received 27 July 2012; accepted 1 August 2012; published 15 August 2012.
}

Observations of ocean surface currents by means of oceanographic buoys drifting on a surface (drifters) are carried out throughout many years. In the last years, thanks to the global ocean observing system created by the international efforts, not less than 1250 buoys regularly distributed over the World Ocean have been drifting simultaneously. Data of observations are transferred via satellite communication systems to the acquisition coastal centers. Every day from drifters there come data flows which should be archived, processed, visualized, analyzed and conclusions need to be done. The present article is devoted to the description of the computer system of storage, processing and visualization of drifter data - the system which has been functioning already for more than 10 years at the State Oceanographic Institute of the Russian Federal Hydrometeorology and Environmental Monitoring Service. In the interactive mode the system gives the data of observations, including averaged grid sets, as well as the various graphical and statistical information on the measured currents and temperature in a surface layer of any given area of the World Ocean. KEYWORDS: Information system; database; data processing; visualization; drifter observations; surface currents; World Ocean.

Citation: Nikitin, O. P. (2012), Storage, processing and visualization data system of drifter observations of surface currents in the World Ocean, Russ. J. Earth. Sci., 12, ES5002, doi:10.2205/2012ES000521.

\section{Introduction}

Drifter observations in a surface layer of the World Ocean have been conducting already for more than a century. However drifters deployed earlier, for example, freely floating heavy meteorological buoys were not quite appropriate to measurements of currents. The most suitable to measurement of actual currents, - the Lagrangian drifters - were started being used widely within the limits of the long-term Surface Velocity Program (SVP) since 1988 [Niiler, 2001]. The Lagrangian SVP drifter consists of a surface spherical buoy of the small size with sensors, controller and radio transmitter established on it and the underwater sail-drogueanchor connected to the buoy by means of a rope. The sail represents the cylinder of a rather big size which centre settles down in 15 meters below a surface. The underwater sail considerably minimizes influence of surface waves and a wind on a surface buoy. Besides the data about a drifter location, the information on measured parameters of environment close to the ocean surface is transmitted via satellite channels as well. Nowadays all drifters have the water

\footnotetext{
${ }^{1}$ N. N. Zubov State Oceanographic Institute, Moscow, Russia
}

Copyright 2012 by the Geophysical Center RAS.

http://elpub.wdcb.ru/journals/rjes/doi/2012ES000521.html temperature sensor; many of drifters are equipped with the sensor of air pressure.

Within the limits of the SVP, the drifter data are passed through a preprocessing and quality control in the Atlantic Oceanographic and Meteorological Laboratory (AOML, USA). The checked data are interpolated with a sixhour interval. The most of these data are accessible through the web-site of AOML. However, the part of data is inaccessible and, consequently, it is necessary to use other sources of drifter data. One of such sources, the Canadian Integrated Science Data Management (ISDM) service stores raw, not quality controlled, not interpolated on time, operative data of drifter observations.

\section{General Description of the Developed System of Storage, Processing and Visualization of Data of Drifter Observations}

For already more than 10 years the acquisition of all accessible data of drifter observations over surface currents of the World Ocean is carried out at the State oceanographic institute (SOI) of the Federal Hydrometeorology and Environmental Monitoring Service of Russia. It is necessary to 


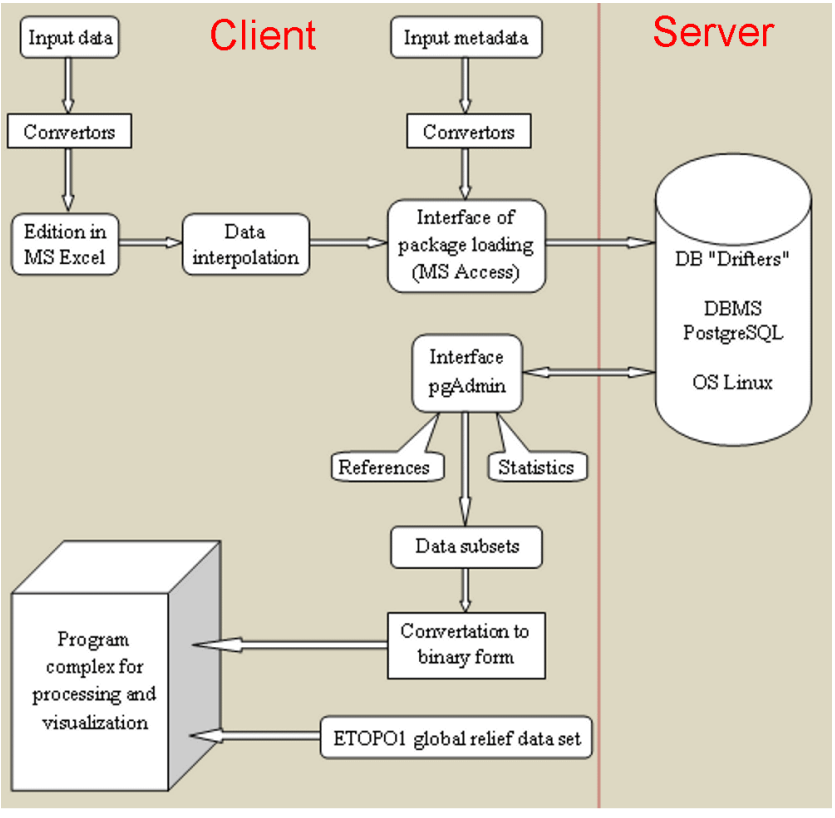

Figure 1. The scheme of the system of storage, processing and visualization of drifter data.

notice, that such acquisition represents an uneasy problem as the proprietors of drifter data often do not give data in a free public use and it is necessary to address for the data directly to them. For example, in AOML less than 30 percent of data of drifter observations in the Black sea are in the open access in relation to the volume of the information which has been collected finally in SOI.

The system of storage, processing and visualization developed in SOI is based on the constantly filled up global historical (1979-2011) data set of drifter observations. The technological scheme of the system is represented in Figure 1.

System software is grouped around two basic products a relational server-based database of drifter measurements of currents velocities and temperature of water in a surface layer of the World Ocean (on the scheme - DB "Drifters") and the interactive program complex for drifter data visualization, calculation of grid and statistical characteristics (on the scheme - Program complex for processing and visualization).

When drifter data are being gathered, they are copied from various sources. Two problems arise: elimination of doubles and convertation to the uniform format because a big variety of formats of drifter data and systems of their numbering can be observed. Data can be presented in various text and binary formats (MATLAB, NetCDF). For comparison of data, they are preliminary converted to the uniform format of Microsoft Excel. Further the preliminary visual control, revealing of poor-quality drifter data and elimination of doubles are carried out in the Excel program. Further, if the data obtained are not interpolated on time, the smoothing interpolation of data with standard six-hour step is carried out. After control and edition of the initial data and metadata are made, the prepared information is distributed over tables of the intermediate database on the basis of Microsoft Access for the subsequent package loading in the DB "Drifters". These tables are the same as the tables of the DB "Drifters". Final clearing of the united set of drifter data from doubles is carried out at loading in the DB "Drifters", as its structure does not allow the duplicated data to be written down and stored. Secondary control and edition of drifter data is carried out by means of DB "Drifters" and in a process of data mapping.

\section{Description of the Database "Drifters"}

DB "Drifters" was designed for the purpose of convenient storage and management of global historical data set, search and retrieval of information, as well as for data controlling and editing. As a tool for the development of the logical scheme of DB "Drifters", the CASE tool ERwin was applied at the design stage. Specific data obtained by drifters (coordinates, date and time of location, components and modulus of current velocity, water temperature, measurement errors), meta-information to the drifter data, including identification numbers of the drifter in various classification systems, name of the drifter manufacturer, type of the buoy and sensors used for drift measurements, data on the experiment in which the drifter was deployed, the coordinates of a point and time of loss of the subsurface drifter's sail, the reason for termination of measurement by means of a drifter, etc., are reflected in the logic scheme of DB in the form of entities and attributes.

The database project was realized in the environment of the post-relational database management system (DBMS) PostgreSQL on the basis of the Linux Red Hat operating system (OS) on the SOI server (Figure 1). The PostgreSQL DBMS architecture allows using DB "Drifters" in the client-server mode and in the multiuser regime. DBMS PostgreSQL is focused on the TCP/IP protocol this can be a local network or Internet. Client applications can be developed in the user-friendly Windows environment. By means of the ODBC driver it is possible to work with the database placed in PostgreSQL, using office Microsoft Access and Excel programs.

For the work with the current version 9.1 of the PostgreSQL DBMS installed on the SOI server, the issued graphic interface pgAdmin of the third generation (pgAdmin III) is used. The interface should be installed in the Windows environment on the client computer of the "Drifters" DB user. Unfortunately, pgAdmin III (unlike pgAdmin II) doesn't contain the master of the data import and the input of mass information in the "Drifters" DB is carried out now by means of the DBMS Access. Retrieval of information from the "Drifters" DB is carried out by means of the pgAdmin III interface. Interaction with the server program (postmaster PostgreSQL), which constantly works waiting for clients connection and carries out the given tasks on their behalf with the databases placed in PostgreSQL DBMS, is maintained out through the SOI local network according to the TCP/IP protocol by means of the psqlODBC driver. After connection to the postmaster 
PostgreSQL program by means of the pgAdmin III interface it is possible to create, look through and change or delete various objects of DB "Drifters"; by means of SQL-queries it is possible to make retrievals of drifter data subsets, to receive various references and statistical reports on data and metadata.

At the moment of writing this article, the data set of global drifter observations of surface currents of the World Ocean loaded into the "Drifters" DB covered the period from February, 1979 till January, 2012 and amounted to $24,841,765$ records of currents velocities (measurements) received from 16,202 drifters. The number of measurements corresponding to one drifter varies in a wide range from 2 to 12,439 and makes 1533 on the average. Thus, duration of observations by means of a drifter on the average makes 383 days though 67 drifter-long-livers transmitted information more than 6 years, and 6 drifters -8 years.

\section{Program Complex for Visualization, Calculation of Grid Fields, Statistical Characteristics and Animation of Data of Drifter Observations}

For processing and visualization of information on surface currents and water temperature contained in the data of drifter observations, the interactive program complex functioning on the OS Windows platform (in Figure 1 - Program complex for processing and visualization) was developed. Together with the global drifter data set or subset prepared with the help of DB "Drifters" and the global data set of bottom relief, which are presented in the binary form, the complex allows making all-round processing and visualization of drifter and relief data. Currently the known one-minute global data set ETOPO1 [Amante and Eakins, 2009 of the relief of a surface of the Earth which combines land topography and ocean bathymetry, is used in the system. "Ice surface" version of ETOPO1, depicting the top of the Antarctic and Greenland ice sheets, instead of the "Bedrock" (base of the ice sheets) version is used.

The program complex is developed in the environment of the Compaq Visual Fortran. Standard Windows interface is used: multilevel menus, windows and dialogues. In the complex the modular structure of management is realized by means of pressing the buttons of the multilevel menus which evoke functional modules.

The complex allows real time calculating and representing on the monitor's screen maps and graphs of various characteristics of currents velocities and temperature in a surface layer of any chosen region of the World Ocean for various, chosen in dialogues space-time intervals. Maps of drifter trajectories, vector and module of velocity, kinetic energy, coefficient of stability of currents, temperature of a surface of the ocean, bottom relief etc., are represented and saved in graphic files. Calculations of various given grid fields and statistical characteristics of current velocities and water temperature, graphs of annual and interannual variation of various characteristics are carried out. Any trajectory can be chosen by mouse on any summary map of trajectories for its detailed digital analysis and creation of graphs of time variability of components, module and vector of velocity and temperature along trajectory as well. Animated reproduction of moving of an ensemble or separate drifters with surface currents is also possible.

\section{Some Examples of the Cartographical Products of the System}

Figure 2 presents an ensemble of all drifting buoys trajectories in the World Ocean, data of which are stored in DB "Drifters". The ensemble is drawn by means of the program complex of the system.

Alternative representation of the coverage of the World Ocean by drifter observations can be seen in Figure 3 - it is a map of distribution of the drifter measurements number in rectangles with sides of $6 \times 3$ degrees, respectively, for the geographical longitude and latitude.

As it can be seen, the increased density of drifter measurements corresponds to the global ocean belt between $\sim 50^{\circ} \mathrm{S}$ and $\sim 50^{\circ} \mathrm{N}$ latitudes. Near-polar regions, a number of coastal ocean areas and some seas are characterized by a low or zero density of measurements.

To support a global array of observations over surface currents, deployment of $\sim 1000$ drifting buoys are annually made. Figure 4 shows initial points of drift of buoys (points of buoys launching), constructed according to DB "Drifters" for the period from 1979 to 2011.

Figure 5 shows an assemblage of parts of drifting buoys trajectories where velocities of buoys exceeded $1 \mathrm{~m} \mathrm{~s}^{-1}$. This assemblage demonstrates areas of strong currents in the World Ocean. It is important to note that such demonstration could be possible due to the usage of the drifting buoys data.

The considered computer system provides incomparably more information of surface ocean currents and temperature, than existing paper atlases. Similar atlases and, in particular, Atlas of oceans [Atlas of the Oceans, 1974-1980] which has not been republished for a long time, are based on approximate calculation methods and consequently show very simplified, schematic picture of ocean currents. By means of the described computer system, there appeared a possibility of creating more accurate and detailed modern maps of surface currents on the basis of data of their direct measurements by means of drifting oceanographic buoys. As it seen from Figure 2 and Figure 3 by now rather representative long-term sets of such data are stored up already for many regions of the World Ocean.

As an example, in Figure 6 the map of surface currents in the Norwegian basin is provided. The map is constructed on the basis of drifting buoys data.

For comparison, in Figure 7 the map of surface currents for the same area taken from the Atlas of oceans [Atlas of the Oceans, 1974-1980 is shown; this map was constructed on the basis of hydrographic data and calculations on a rough 5-degree grid. 


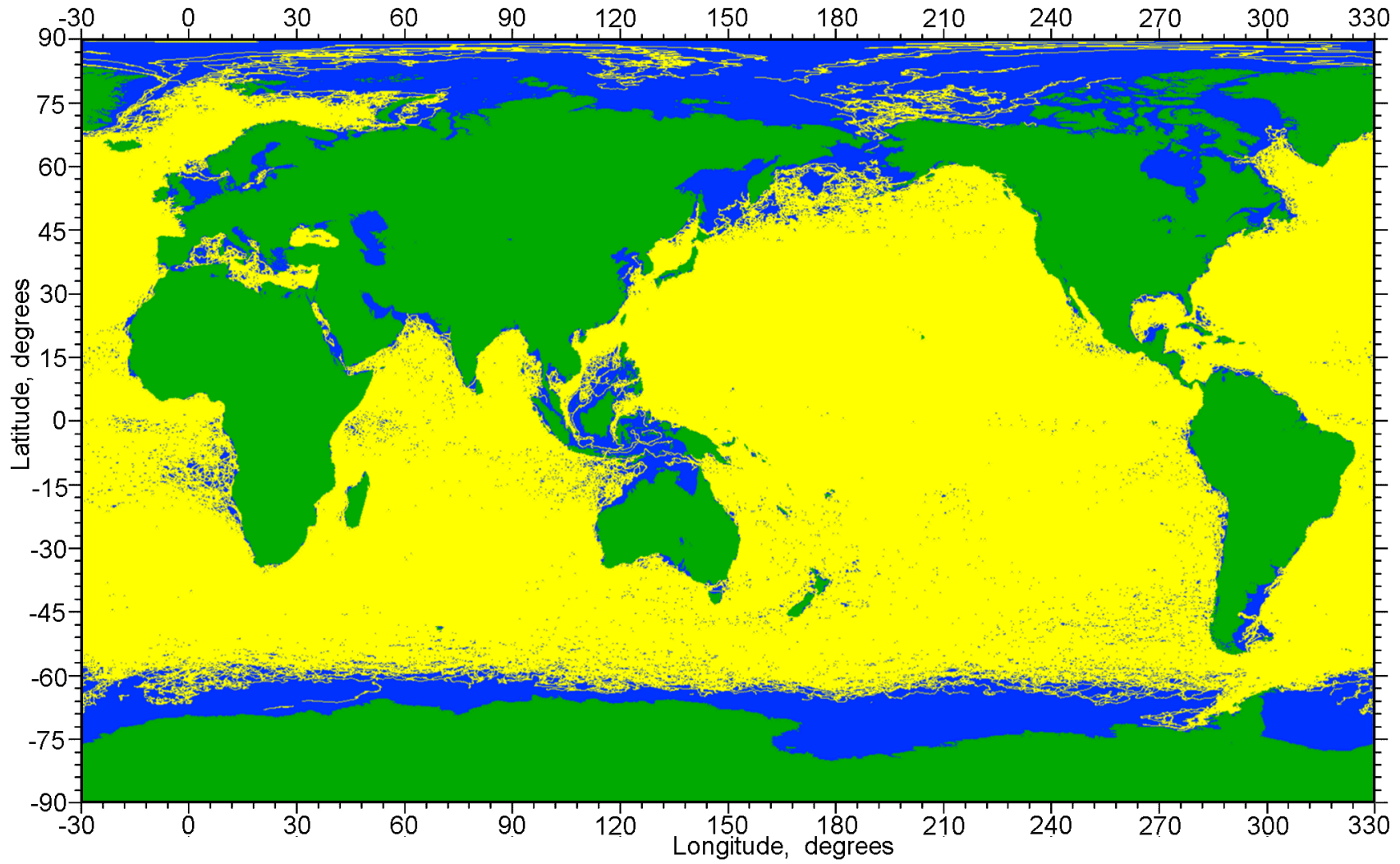

Figure 2. Coverage of the World Ocean by drifter observations. The map is constructed by trajectories (are represented in yellow color) of drifting buoys from 15.02.1979 till 31.12.2011.

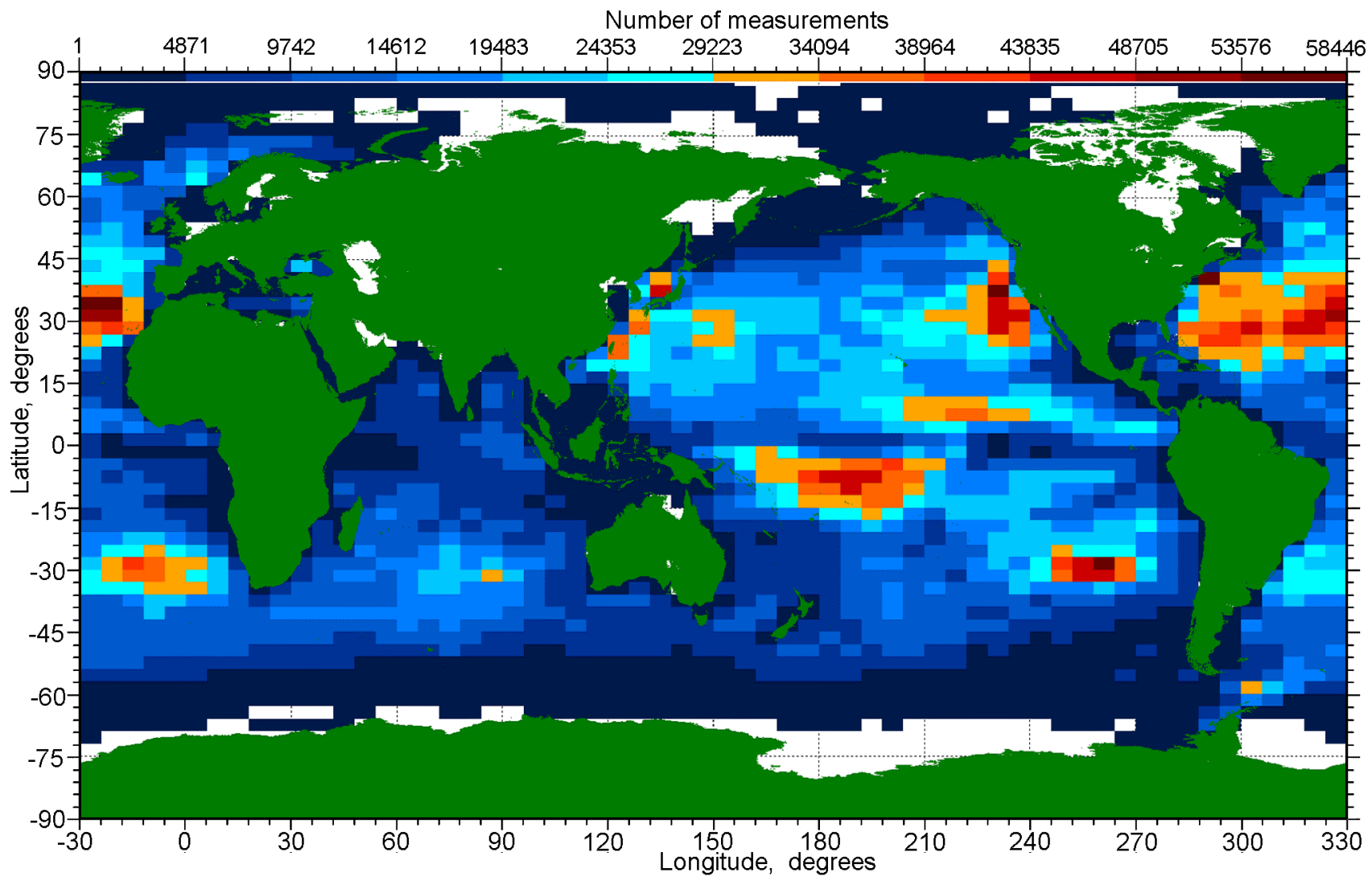

Figure 3. Distribution of the number of drifter measurements in space. There is a horizontal colour scale and divisions with numbering in the top part of the map. 


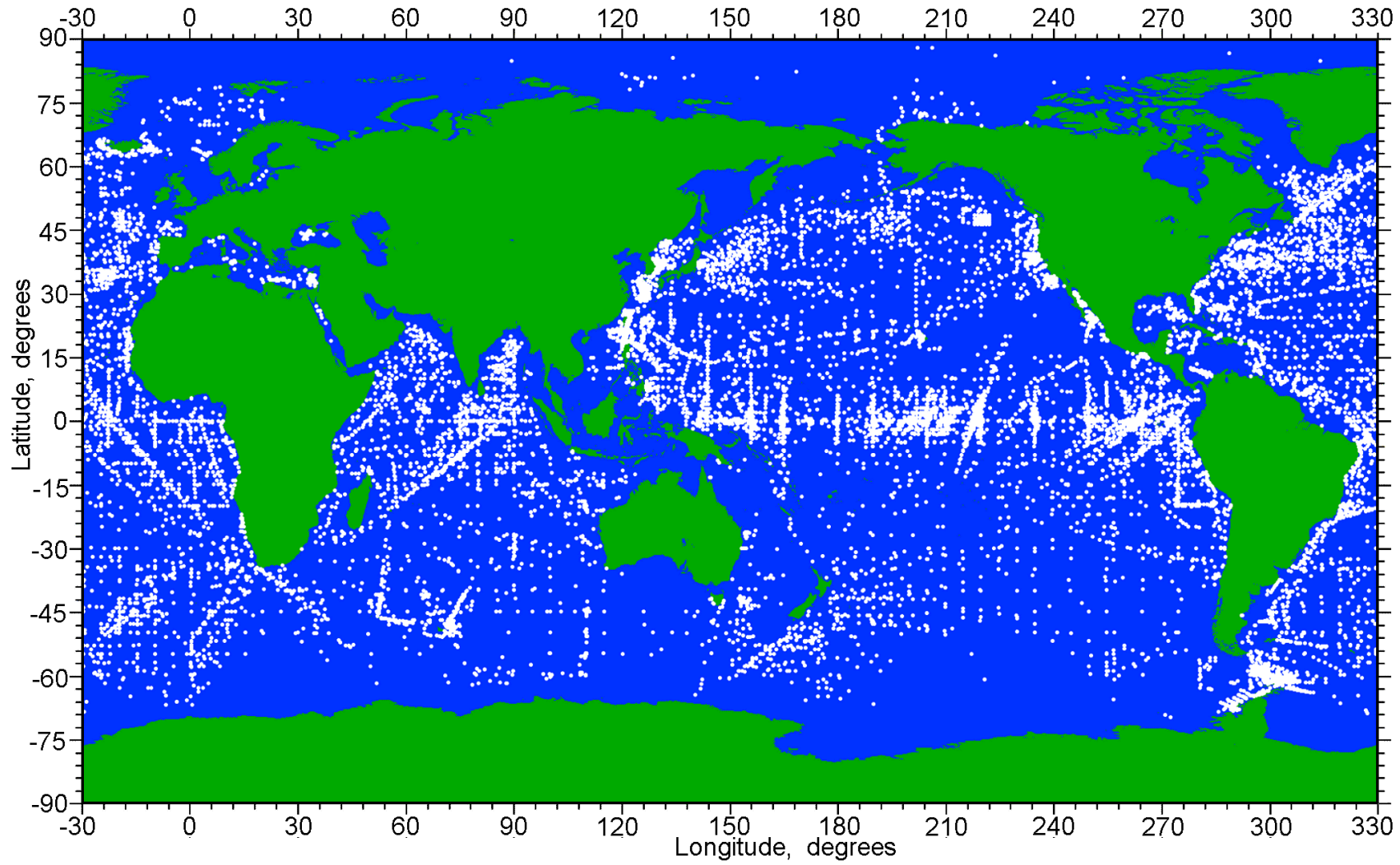

Figure 4. Points of drifter launching in the period of 1979-2011.

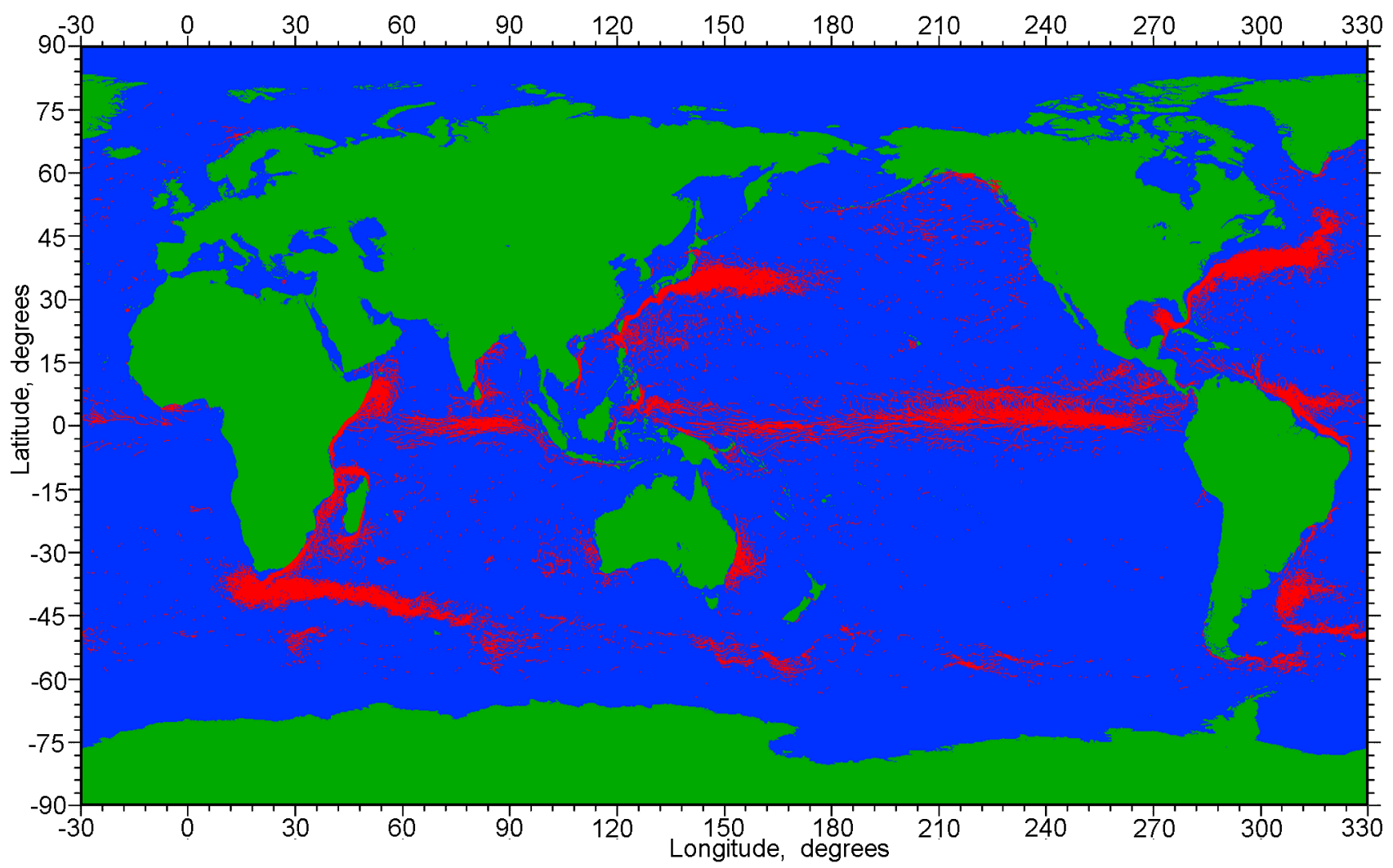

Figure 5. Strong currents in the World Ocean: parts of trajectories where velocities of drifters exceeded $1 \mathrm{~m} \mathrm{~s}^{-1}$ are represented in red color. 


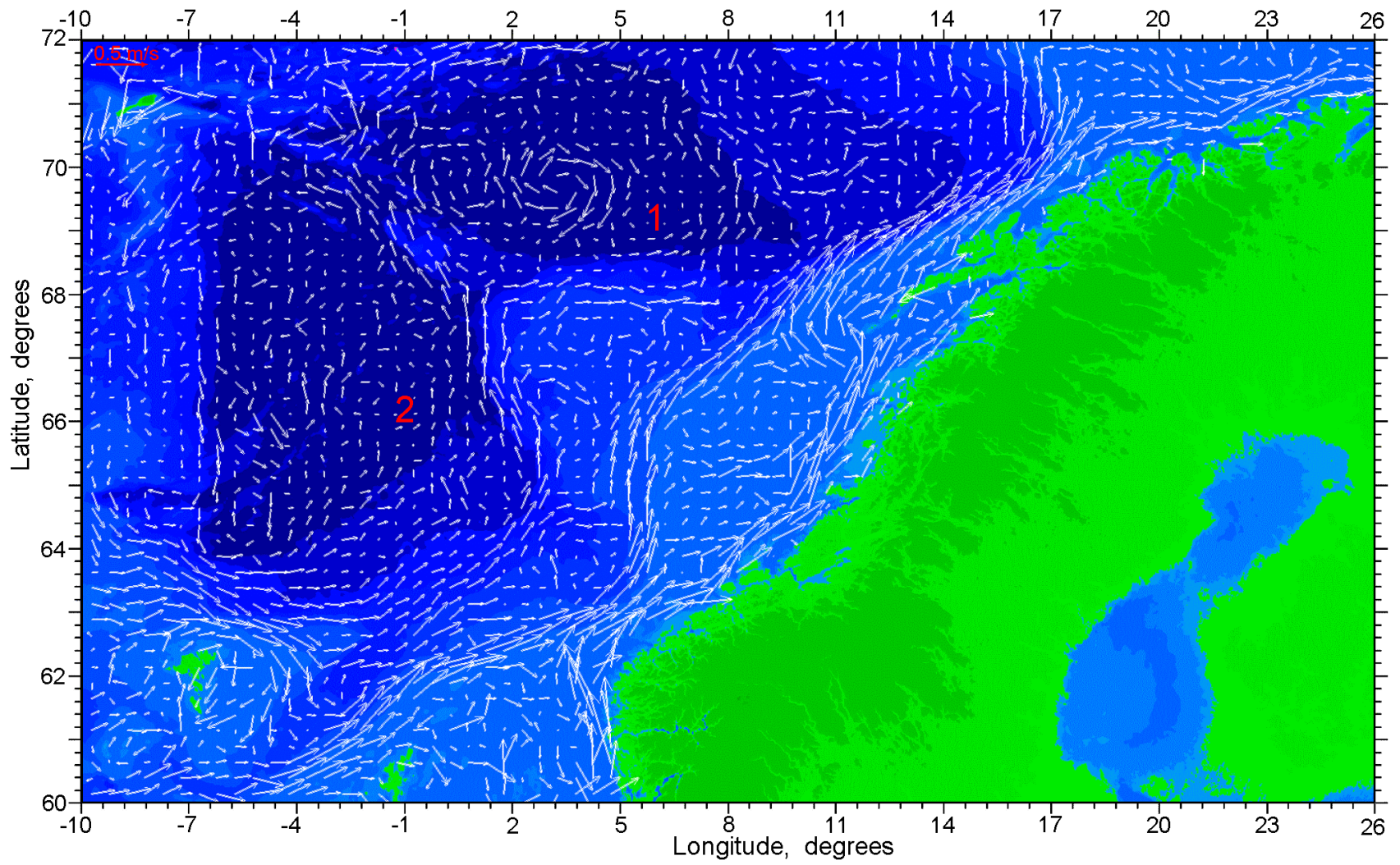

Figure 6. Velocity vectors of average surface currents in the Norwegian basin. The map is constructed with the help of drifter data, averaged over the observation period from 1991 to 2011 and over the grid cells with steps $0.25^{\circ}$ along latitude and $0.5^{\circ}$ along longitude. The scale vector of velocity is shown on the map top. Isobaths correspond to depths 20, 100, 500, 1000, 1500, 2000, 2500, 3000, 4000 and $6000 \mathrm{~m}$, isohypses - to heights 100, 500 and $2000 \mathrm{~m}$. Lofoten and Norwegian hollows are indicated by 1 and 2 (in red color).

Comparison of Figure 6 and Figure 7 shows that the maps of currents with the drawn velocity vectors, taken from the Atlas of oceans, are quite inexact. From the map presented in Figure 6 it is seen that the Norwegian current flowing along the coast of Norway on the northeast, is not a single stream, but two flows which meet at one place and disperse at another one. Stationary water eddies along the western periphery of the Norwegian current, and also in the areas corresponding to Lofoten and Norwegian deep-water hollows are visible also, whereas they are not shown in Figure 7 The anti-cyclonic water eddy over the Lofoten hollow is most clearly seen. From the West it is adjoined by the cyclonic eddy, forming, thus, the dipole. It is possible also to note that around the whole Norwegian hollow there is a cyclonic circulation of waters following deep-water isobaths. In general it should be noted that bottom relief which can be located in thousand meters below the sea level, influences considerably on the directions of surface currents in the considered basin. Such influence is observed also in some other regions of the World Ocean. For this reason the possibility of displaying the bottom relief on maps of surface currents velocity vectors and trajectories of drifters, is provided in the developed system.

\section{Conclusions}

The developed interactive system allows carrying out both graphic constructions and other calculations, including statistical one, promptly, in the on-line regime for any given region of the World Ocean, by the global set of drifter data available at the moment (periodically replenished). Time response of the system for queries on the modern personal computer makes from several seconds to several hours depending on a type of a query and the size of the area. The described system continues to be developed and enriched with new options and possibilities.

By means of this system it is possible to receive quickly the demonstration of structure and space-time variability of currents and temperature in a surface layer of any region of the World Ocean with necessary detail or generalization. The system can be useful in the analysis of dynamics of waters of the ocean upper layer, in studying the transfer of heat and polluting substances, in investigating the influence of variability of the ocean circulation on changes of weather and climate, validation and tuning of hydrodynamic models of circulation. 


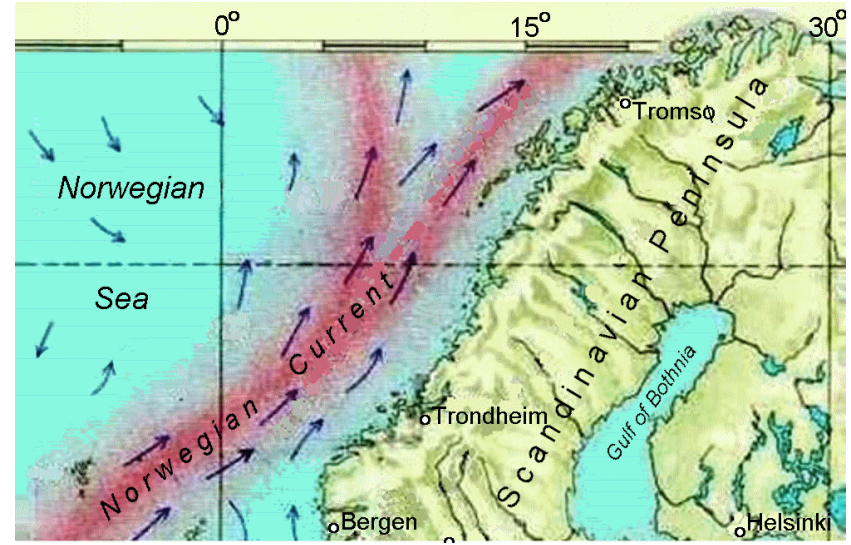

Figure 7. Currents in the Norwegian sea according to the Atlas of oceans.

Products of this system have been used quite often within the last 14 years in various projects and for responding the inquiries from various organizations, including governmental and foreign ones.

In 1999 by means of the system, a great deal of gross errors were found in the set of drifter data (1989-1998), prepared within the international World Ocean Circulation Experiment (WOCE) and placed on the server of the authorized Canadian center ISDM of archiving of drifter data, and also on the compact disc prepared for the WOCE-1998 conference in Halifax (Canada). After systematization and classification of the found errors, a report was prepared which was discussed at the meeting of the WOCE Data Products Committee [Nikitin, 2000]. As a result of the discussion, the decision was made that the drifter data which were in open access on the ISDM WWW-server, were to be additionally edited and replaced considering the remarks made in the report.

Information on surface currents prepared by means of the system, was provided in 2000 for the region of the destruction of the nuclear submarine "Kursk" in the Barents Sea, and in 2009 for the area of falling of the French plane A-330 in the tropical Atlantic. In 2002 the system was used for responding the inquiry of the Russian Ministry of Foreign Affairs about probability of transport of the oil pollution in the northern part of the Pacific Ocean by surface currents from the American coast of Alaska towards the Russian Kamchatka, and in 2011 - for determination of paths of propagation of the radioactive pollution due to accidents (after the tsunami blow) on the nuclear power plant "Fukushima-1" [Nikitin and Kasyanov, 2012 .

Basing on the work experience, the author recommends the Ministry of Emergency Situations of Russia to have 510 drifters (each transmitting the information about its own location via the system of satellite communication) ready to be dropped quickly from the plane to the area of sea accident for easier search of people, wreckage of ships and planes, determination of the direction of the pollution transport, including radioactive one.

\section{References}

Amante, C., B. W. Eakins (2009), ETOPO1 1 arc-minute global relief model: procedures, data sources and analysis,, NOAA Technical Memorandum NESDIS NGDC-24, National Geophysical Data Center, Marine Geology and Geophysics Division, Boulder, Colorado, 1-25.

Ministry of Defense of USSR, Navy (1974-1980), Atlas of the Oceans, Series of three volumes: Pacific, Atlantic and Indian, Arctic Oceans, the Ministry of Defense of USSR, Navy, (in Russian).

Niiler, P. (2001), The World ocean surface circulation, in: Ocean circulation and climate, G. Siedler, J. Church, J. Gould (eds.), Academic press, San Diego, 193-204.

Nikitin, O. P. (2000), Report on WOCE SVP Global Data on the CD-ROM, in: WOCE International Project Office 2000. Report of the Thirteenth Meeting of the WOCE Data Products Committee, Texas A\&M University, College Station, TX, USA, WOCE Report No. 170/2000, Appendix B.

Nikitin, O. P., S. Ju. Kasyanov (2012), Surface currents around Japanese islands: paths of propagation of radioactive pollution due to accidents on the nuclear power plant "Fukushima-1", Terra Humana, 2, (in Russian).

O. P. Nikitin, N. N. Zubov State Oceanographic Institute, Moscow, Russia. 